\title{
On-line Measuring Method of Power Frequency Impedance Parameters for Asymmetric Transmission Lines
}

\author{
Ranchen Yang ${ }^{1, a}$, Xuan Yao ${ }^{1, b}$ and Weichen Yang ${ }^{1, c}$ \\ ${ }^{1}$ School of Electrical and Electronic Engineering, North China Electric Power University, Baoding, \\ Hebei 071003, China \\ ayangranchenyrc@126.com, ${ }^{\text {b906697570@qq.com, }{ }^{c} x i a o p e i y a n g @ o u t l o o k . c o m ~}$
}

Keywords: online measurement, asymmetric transmission lines, power frequency impedance parameters, least squares method, simulation

\begin{abstract}
Traditional off-line line parameters measuring is complicated in operation and has poor applicability. And the symmetry of line parameters influences the choice of on-line measurement methods. Generally, it's is asymmetric. Therefore, the paper proposes an on-line measuring method of power frequency impedance parameters for asymmetric transmission lines. First, three-phase unbalanced transmission line model are built and power frequency impedance parameters calculation equations are obtained. The equations are underdetermined and have no specific solutions. By changing the line topology, multiple measurement are preformed and plenty sets of data are obtained. Then after adopting the least squares method in complex domain, the exact solutions are finally derived. The simulation results show that the errors of zero sequence impedance mode and impedance angle reach $-0.2501 \%$ and $0.1533 \%$ respectively, the errors of positive sequence impedance mode and impedance angle reach $-0.1974 \%$ and $0.1011 \%$ respectively, far less than the error requirement of practical engineering. The method in this paper is of high accuracy, which can provide a theoretical basis for three-phase unbalanced transmission line parameters on-line measurements.
\end{abstract}

\section{Introduction}

Measuring the power frequency parameters accurately is a kind of necessary work to ensure normal transmission of electrical energy. Since it is difficult to calculate the environment impact on the line parameters accurately, using the factory parameters as wire line parameters is clearly inappropriate. Traditional off-line measurement method has the drawbacks such as complicated operation, poor applicability while on-line measurement can address them. It doesn't require power which can prevent the loss of power lines and improve the economy and reliability of the system. Besides, it can achieve real-time status detection. Some parameters of the line will change with the operating status changes, such as system overloading leading to line heating resistance increasing and line sag rising. Online measurement can find some safety problems as early as possible and remove them immediately.

Therefore, this paper proposes a power frequency transmission line impedance parameters on-line measuring method. Online measuring requires to collect multiple sets of data from long distance synchronically, which can be use GPS technology-based wide area measurement system WAMS. Its principle is as follows. First sampling. Next perform signal analysis with digital signal processing method. Then transmit signal separately to both line ends which are granted time stamp by GPS synchronization. Ultimately, the synchronical intelligent detection of signal is achieved.

The proposed line parameters measuring method in this paper takes into account the situation of asymmetry parameter line. Under this circumstance, symmetrical components method can't be used any longer. So, the paper figures out a new way.

\section{The Model of Three-phase Unbalanced Transmission Line}

The circuit theory shows that any two-port network which does not contain the power source can be equivalent to $\Pi$ type circuit. Built on the basis of the theory, $\Pi$ type equivalent circuit of 
asymmetric three-phase transmission line is shown in Figure 1.

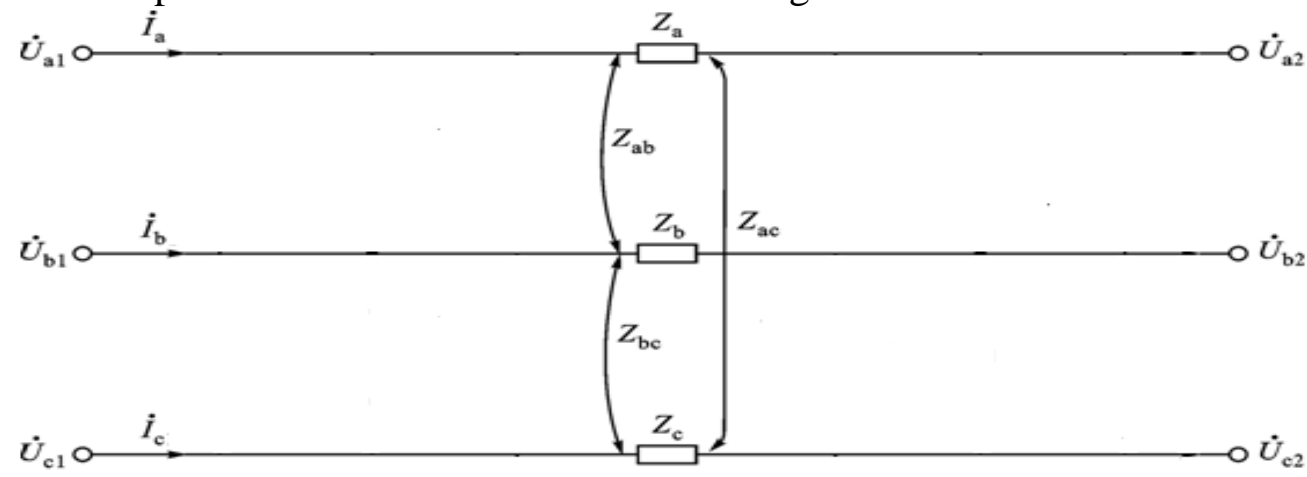

Figure 1 . The $\prod$ type equivalent circuit of asymmetric three-phase transmission line

$\mathrm{Z}_{\mathrm{a}}, \mathrm{Z}_{\mathrm{b}}, \mathrm{Z}_{\mathrm{c}}$ are self-impedance of each phase respectively, and $\mathrm{Z}_{\mathrm{ab}}, \mathrm{Z}_{\mathrm{bc}}, \mathrm{Z}_{\mathrm{ac}}$ are mutual impedance of each two-phase respectively. The algebra equation sets of the above $\Pi$ type equivalent circuit can be described as follows,

$$
\left\{\begin{array}{l}
\mathrm{U}_{\mathrm{a}}=\mathrm{Z}_{\mathrm{a}} \mathrm{I}_{\mathrm{a}}+\mathrm{Z}_{\mathrm{ab}} \mathrm{I}_{\mathrm{b}}+\mathrm{Z}_{\mathrm{ac}} \mathrm{I}_{\mathrm{c}} \\
\mathrm{U}_{\mathrm{b}}=\mathrm{Z}_{\mathrm{ab}} \mathrm{I}_{\mathrm{a}}+\mathrm{Z}_{\mathrm{b}} \mathrm{I}_{\mathrm{b}}+\mathrm{Z}_{\mathrm{bc}} \mathrm{I}_{\mathrm{c}} \\
\mathrm{U}_{\mathrm{c}}=\mathrm{Z}_{\mathrm{ac}} \mathrm{I}_{\mathrm{a}}+\mathrm{Z}_{\mathrm{bc}} \mathrm{I}_{\mathrm{b}}+\mathrm{Z}_{\mathrm{c}} \mathrm{I}_{\mathrm{c}}
\end{array}\right.
$$

Where

$$
\mathrm{U}_{\mathrm{a}}=\mathrm{U}_{\mathrm{a} 1}-\mathrm{U}_{\mathrm{a} 2}, \mathrm{U}_{\mathrm{b}}=\mathrm{U}_{\mathrm{b} 1}-\mathrm{U}_{\mathrm{b} 2}, \mathrm{U}_{\mathrm{c}}=\mathrm{U}_{\mathrm{c} 1}-\mathrm{U}_{\mathrm{c} 2} \text {. }
$$

\section{The Solving of impedance parameters}

According to equation (1), three equations and six unknowns can be obtained. It is obvious that the equations are underdetermined and have no specific solutions. Therefore, by changing the line topology, multiple measurement are preformed and overdetermined equations are obtained.

$$
\left\{\begin{array}{c}
\mathrm{U}_{\mathrm{a}}^{(1)}=\mathrm{Z}_{\mathrm{a}} \mathrm{I}_{\mathrm{a}}^{(1)}+\mathrm{Z}_{\mathrm{ab}} \mathrm{I}_{\mathrm{b}}^{(1)}+\mathrm{Z}_{\mathrm{ac}} \mathrm{I}_{\mathrm{c}}^{(1)} \\
\mathrm{U}_{\mathrm{b}}^{(1)}=\mathrm{Z}_{\mathrm{ab}} \mathrm{I}_{\mathrm{a}}^{(1)}+\mathrm{Z}_{\mathrm{b}} \mathrm{I}_{\mathrm{b}}^{(1)}+\mathrm{Z}_{\mathrm{bc}} \mathrm{I}_{\mathrm{c}}^{(1)} \\
\mathrm{U}_{\mathrm{c}}^{(1)}=\mathrm{Z}_{\mathrm{ac}} \mathrm{I}_{\mathrm{a}}^{(1)}+\mathrm{Z}_{\mathrm{bc}} \mathrm{I}_{\mathrm{b}}^{(1)}+\mathrm{Z}_{\mathrm{c}} \mathrm{I}_{\mathrm{c}}^{(1)} \\
\quad \vdots \\
\mathrm{U}_{\mathrm{a}}^{(\mathrm{m})}=\mathrm{Z}_{\mathrm{a}} \mathrm{I}_{\mathrm{a}}^{(\mathrm{m})}+\mathrm{Z}_{\mathrm{ab}} \mathrm{I}_{\mathrm{b}}^{(\mathrm{m})}+\mathrm{Z}_{\mathrm{ac}} \mathrm{I}_{\mathrm{c}}^{(\mathrm{m})} \\
\mathrm{U}_{\mathrm{b}}^{(\mathrm{m})}=\mathrm{Z}_{\mathrm{ab}} \mathrm{I}_{\mathrm{a}}^{(\mathrm{m})}+\mathrm{Z}_{\mathrm{b}} \mathrm{I}_{\mathrm{b}}^{(\mathrm{m})}+\mathrm{Z}_{\mathrm{bc}} \mathrm{I}_{\mathrm{c}}^{(\mathrm{m})} \\
\mathrm{U}_{\mathrm{c}}^{(\mathrm{m})}=\mathrm{Z}_{\mathrm{ac}} \mathrm{I}_{\mathrm{a}}^{(\mathrm{m})}+\mathrm{Z}_{\mathrm{bc}} \mathrm{I}_{\mathrm{b}}^{(\mathrm{m})}+\mathrm{Z}_{\mathrm{c}} \mathrm{I}_{\mathrm{c}}^{(\mathrm{m})}
\end{array}\right.
$$

Where $\mathrm{U}_{\mathrm{a}}^{(\mathrm{i})}, \mathrm{U}_{\mathrm{b}}^{(\mathrm{i})}, \mathrm{U}_{\mathrm{c}}^{(\mathrm{i})}, \mathrm{I}_{\mathrm{a}}^{(\mathrm{i})}, \mathrm{I}_{\mathrm{b}}^{(\mathrm{i})}, \mathrm{I}_{\mathrm{c}}^{(\mathrm{i})}$ are respectively the $\mathrm{i}$ $(\mathrm{i}=1,2, \ldots, \mathrm{m}, \mathrm{m}$ is the measuring times, $\mathrm{m} \geq 2$ ) time measured values of line voltages and currents phasor.

Transfer equation (2) into matrix form,

$$
\dot{\mathrm{U}}=\dot{\mathrm{I} Z}
$$

Where

$$
\begin{aligned}
& \dot{U}=\left[U_{\mathrm{a}}^{(1)} \mathrm{U}_{\mathrm{b}}^{(1)} \mathrm{U}_{\mathrm{c}}^{(1)} \ldots \mathrm{U}_{\mathrm{a}}^{(\mathrm{m})} \mathrm{U}_{\mathrm{b}}^{(\mathrm{m})} \mathrm{U}_{\mathrm{c}}^{(\mathrm{m})}\right]^{\mathrm{T}} \\
& \mathrm{Z}=\left[\begin{array}{lllll}
\mathrm{Z}_{\mathrm{a}} & \mathrm{Z}_{\mathrm{b}} & \mathrm{Z}_{\mathrm{c}} & \mathrm{Z}_{\mathrm{ab}} & \mathrm{Z}_{\mathrm{bc}} \\
\mathrm{Z}_{\mathrm{ac}}
\end{array}\right]^{\mathrm{T}}
\end{aligned}
$$




$$
\dot{\mathrm{I}}=\left[\begin{array}{cccccc}
\mathrm{I}_{\mathrm{a}}^{(1)} & 0 & 0 & \mathrm{I}_{\mathrm{b}}^{(1)} & 0 & \mathrm{I}_{\mathrm{c}}^{(1)} \\
0 & \mathrm{I}_{\mathrm{b}}^{(1)} & 0 & \mathrm{I}_{\mathrm{a}}^{(1)} & \mathrm{I}_{\mathrm{c}}^{(1)} & 0 \\
0 & 0 & \mathrm{I}_{\mathrm{c}}^{(1)} & 0 & \mathrm{I}_{\mathrm{c}}^{(1)} & \mathrm{I}_{\mathrm{a}}^{(1)} \\
\vdots & \vdots & \vdots & \vdots & \vdots & \vdots \\
\mathrm{I}_{\mathrm{a}}^{(\mathrm{m})} & 0 & 0 & \mathrm{I}_{\mathrm{b}}^{(1)} & 0 & \mathrm{I}_{\mathrm{c}}^{(1)} \\
0 & \mathrm{I}_{\mathrm{b}}^{(\mathrm{m})} & 0 & \mathrm{I}_{\mathrm{a}}^{(1)} & \mathrm{I}_{\mathrm{c}}^{(1)} & 0 \\
0 & 0 & \mathrm{I}_{\mathrm{c}}^{(\mathrm{m})} & 0 & \mathrm{I}_{\mathrm{c}}^{(1)} & \mathrm{I}_{\mathrm{a}}^{(1)}
\end{array}\right]
$$

The impedance parameters matrix is as follows,

$$
\mathrm{Z}=\left(\dot{\mathrm{I}}^{\mathrm{T}} \dot{\mathrm{I}}\right)^{-1}\left(\dot{\mathrm{I}}^{\mathrm{T}} \dot{\mathrm{U}}\right)
$$

After adopting the least squares method in complex domain, the exact solutions are finally derived.

\section{Digital Simulation Results}

According to the above method, the impedance parameters for asymmetric three-phase transmission lines are simulated under the measurement cases for unbalanced load.

The length of three-phase transmission line is $20 \mathrm{~km}$. The voltage level of the lines source is 220 $\mathrm{kV}$ and the load is $100 \mathrm{MW}$. Use the above method, put the measured voltage and current data into the computer and calculate zero sequence impedance and positive sequence impedance. The results are shown in Table 1 . The simulation results validate the on-line measurement method is correct.

Table1. Digital Simulation Results

\begin{tabular}{|c|c|c|}
\hline & Zero sequence impedance & Positive sequence impedance \\
\hline Parameters & $1.2721 \angle 76.0234^{\circ}$ & $0.3233 \angle 87.8921^{\circ}$ \\
\hline Measuring values & $1.2753 \angle 76.1399^{\circ}$ & $0.3239 \angle 87.8032^{\circ}$ \\
\hline Relative error\% & $-0.2501 / 0.1533$ & $-0.1974 / 0.1011$ \\
\hline
\end{tabular}

The simulation results prove that the errors of zero sequence impedance mode and impedance angle reach $-0.2501 \%$ and $0.1533 \%$ respectively, the errors of positive sequence impedance mode and impedance angle reach $-0.1974 \%$ and $0.1011 \%$ respectively. They are all of high accuracy, far less than the error requirement of practical engineering.

\section{Conclusion}

Based on the circuit theory, the paper firstly built three-phase unbalanced transmission line circuit model, through which we can obtain the transmission line power frequency impedance parameters calculation equations. They are underdetermined equations. For this reason, it need more groups of measuring data by changing the network topology such as from line run to run-off or from adding experiment power to removing several times. By the least squares data processing method in complex domain, a new method of impedance parameters calculation equations is given. The more measured data, the more accurate the results are. In conclusion, the method in this paper can not only measure self-impedance and mutual impedance of transmission lines on-line, but also solve the power lines' asymmetry impact. Besides, simulation results have proved the correctness and accuracy of the method, which provide a theoretical basis for three-phase unbalanced transmission line parameters on-line measurements.

\section{References}

[1] Bangrui Gong, ”Study on Power Frequency Parameter Online Measurement of Transmission Line”, [D] North China Electric Power University, 2013.

[2] Jinquan Zhao, Jianhua Yin, Jiansheng Xia, Yanjun Zhao, Huanrui Liu, Yan Gao, “An Online Measuring Method of the Parameters for Asymmetric Transmission Lines”, Journal of Xi'an 
Jiaotong University, Vol.50, No.2, 2016, pp.80-84.

[3] Zhijian Hu, Yunping Chen, Nin Hu, Zhouwen Zhong, Zhuqin Hong. "New Live Line Measurement Methods of Transmission Lines Inductance Parameters Based on GPS”. Proc.2004. International Conf. on Power System Technology. 2004.

[4] Xue Pan, "Transmission line parameter online calculating method research”,[D] College of Electrical Engineering of Chongqing University, Chongqing, China, 2011.

[5]Zhirui Liang, Changqing Wu, Haifeng Su, Shengsuo Niu, Shuo Zhang, “”, [J] Power System Protection and Control, Vol.40, No.8, 2012, pp.126-130.

[6] Zhongzhu Xu, Zhijian Hu, Chuanqi Li, "Live Line Measuring the Parameters of $220 \mathrm{kV}$ Transmission Lines with Mutual Inductance in Hainan Power Grid”, [J] Engineering, Scientific Research Publishing, Vol.05 (01), 2013, pp.146-151. 